\title{
Hotel theming in China: A qualitative study of practitioners' views
}

\begin{abstract}
Facing increasing competition, many hotels have adopted "theming” as a marketing strategy. Although still in its fledgling stage, hotel theming has already gained popularity in the growing Chinese hotel market. This study conducted focus group discussions to understand the concepts behind hotel theming in China. Respondents were 41 practitioners from the Chinese hotel industry, who were enrolled in an executive graduate program. Data revealed that hotel theming has four analytical dimensions, namely, the current state, perceived facilitators, inhibitors, and future prospective for developing such strategy in China. Results showed that the specific traits of the Chinese hotel market are highly important for the success of hotel theming in the given context.
\end{abstract}

Keywords: theming, hotel, China, marketing, experience economy 


\section{INTRODUCTION}

Although the economic reform in 1978 was a late initiator for the start of tourism in China, this business has experienced phenomenal growth rates (Gu, Ryan, \& Yu, 2012). According to the World Tourism Organization (UNWTO), China will be the most visited tourist destination in the world by 2020, with an estimated arrival number of 135 to 145 million visitors annually (Chan \& Yeung, 2009). The fast growing tourism market has spurred the hotel development in the country, which has seen an investment increase of $6.9 \%$ during the last five years or an estimated USD \$44.1 billion (PRWeb, 2013).

In the past, most Chinese hotels were mainly built for overseas guests or political needs (Gu et al., 2012; Zhang, Pine, \& Lam, 2005). At present, the recent growth in hotel numbers and the emerging domestic market have further fuelled the competition among hoteliers. Past research has reported various issues related to this fast paced development, such as persisting problems in hotel management (e.g., Chan \& Yeung, 2009; Xu, 2012; Zhang et al., 2005), use of outdated technology (Kong, 2006), and domestic hotels being constantly outperformed by international chains (Gu et al., 2012; Pine, 2002). The entry of China in the World Trade Organization (WTO) has largely loosened government control of foreign hotel companies (Pine \& Qi, 2004). Hence, the restrictions of international hotel chains entering the local market have been largely removed. The lifting of the restrictions creates a major threat to domestic hotels because Chinese hotel chains are still considered significantly weaker than their international counterparts (Pine \& Qi, 2004). While many local hotels have subsequently searched for support from foreign chains, individually managed structures have largely underperformed and have struggled to gain competitive edge (Chan \& Yeung, 2009; Pine, 2002). 
The increasing competition in the Chinese hotel market has conceived an unforgiving situation, particularly for local hotels. Apart from the increase of competition in the international scene as a result of the entry in WTO, the rapid growth of domestic hotels has compelled the survival of Chinese hotels in the market even more challenging (Chan \& Yeung, 2009; Pine \& Qi, 2004). In particular, small or medium hotels have to endure major challenges, as they have to compete effectively with more professionally managed and better-financed foreign-run hotel chains (Hung, 2013).

The new practice of Chinese hotel marketing is one particular mechanism that may provide domestic Chinese hotels competitive edge (Kong, 2006). Most domestic hotels are stuck with undifferentiated product and service offerings, absence of market segmentation, a general lack of brand development, and short-term planning. More sophisticated marketing practices, such as niche marketing, are still not widely known although their value has been recognized, particularly for independently managed properties (Chan \& Yeung, 2009).

Theming can be considered a particular form of innovative marketing and a valuable business tool in competitive environments, such as tourism, restaurants, and theme parks (Gottdiener, 2001). The International Theme Hotel Research Institute states that a theme hotel can be defined as "any lodging property that focuses on a certain culture and is equipped with a unique theme design, construction, and decoration in addition to unique facilities in services” (Xiao, Q., Zhang \& Huang, 2013, p. 135). Based on this definition, a themed hotel refers to any lodging establishment that bases its tangible assets (design, décor, facilities, amenities), staff, and intangible assets (e.g., service and activities) on a unique and strong theme, and offers a memorable experience to its guests (Wei, 2005; Xiao, Z., 2012). Xiao et al. (2013) cited hotels in Disney theme parks and casino resorts in Las Vegas, Atlantic City, and Macau as notable 
examples. Hence, theming has been widely used by Western hotels as an innovative marketing tool (Gottdiener, 2001). Although in 2010 the number of theme hotels in China was around 400 and growing (Xiao, X., 2010), studies free of Western paradigm bias and investigating the process and success factors of hotel theming in China are still in short supply.

Theming plays heavily on the experience factors of customers (Kozinets, Sherry, DeBerry-Spence, Duhachek, Nuttavuthisit, \& Storm, 2002). As such, understanding what kind of experience is desired and applying theming to provide an authentic experience are crucial (Muñoz, Wood, \& Solomon, 2006). The means of how this concept applies to a Chinese context has scarcely been investigated (Xiao, et al., 2013). This study focuses on the largely underresearched topic of hotel theming in China by considering the following elements: (1) the cutthroat market environment, (2) the potential for gaining competitive advantages by adopting theming, and (3) the growing demand for policy makers and academics to understand the utility of Western concepts in a Chinese context. This qualitative study aims to understand hotel theming in China from a practitioner's view. In particular, this study aims at understanding (1) how the reality of hotel theming in China is currently perceived by practitioners in light of specific cultural and political contexts, (2) what opportunities, challenges, and added market value of hotel theming in China bring as perceived by practitioners, and (3) how practitioners perceive the future of hotel theming in China.

\section{LITERATURE REVIEW}

By being more informed and knowledgeable, consumers have become complex and hardto-satisfy stakeholders. This development has frequently resulted in a breakdown in distinguishing between firms and users, and placing the latter in the positions of both product designer and creator (Glazer, 1991). To satisfy the increasingly demanding and informed 
consumers, companies need coherence and a significant amount of creativity in their marketing efforts (Giaccari, 2003). These unconventional techniques are employed not merely to reach a large base of consumers, but to provide an underlying meaning and experience to their practices (Schmitt, Rogers, \& Vrotsos, 2004).

Tourism service providers and tourists co-create value and ultimately co-produce an experience product (Li \& Petrick, 2008). Experiential marketing principles have a wide appeal in this field because tourism products are mostly based on experience factors (Kozinets et al., 2002). Pine and Gilmore (1999) stated that experiential marketing is based on the belief that consumers perceive service as increasingly commodified, which diminishes customer satisfaction. This perception has raised the need to offer pure service and deep and memorable experiences for customers. This situation occurs "when a company intentionally uses services as the stage, and goods as props, to engage individual customers in a way that creates a memorable event” (Pine \& Gilmore, 1998, p. 98). Subsequently, experience marketing is believed to have "changed the status of consuming experiences, displacing them from what consumers have personally gone through to participation in a consumption festival dominated by excess, extravagance, magic, spectacularity, and simulation” (Carù \& Cova, 2006, p.10).

Experience staging and selling features the “experience economy” (Pine \& Gilmore, 1999), which was proposed based on the belief that industrial and service economies have their days counted due to lack of innovation and increasing competition (Pine \& Gilmore, 2011). A company decides to provide experiences for its customers by banking on sensory, affective, and creative associations (Smith, 1999). The consumer is subsequently allowed to analyze the experience by means of personal immersion (Carù \& Cova, 2003). By actively or passively participating in the experience economy, customers can have educational, aesthetic, escapist, and 
entertainment experiences (Pine \& Gilmore, 1999). Pine and Gilmore (2011) stated that the successful application of the experience economy has helped various enterprises to survive the 2008 global financial crisis.

Accordingly, every experience must begin from a concise and compelling theme (Pine \& Gilmore, 1999). This theme must be communicated to the customer through adequate sensory inputs, minimizing distractions, offering tangible memorabilia, maximizing sensory experience, and soliciting customer feedback for improvement. A coherent single voice must also be identified throughout marketing communications, support materials, and internal company communications (Petkus Jr., 2004). This mechanism of constructing distinctive and momentous marketing communications is often referred to as "theming."

Theming refers to generating a socially constructed environment that conveys meanings by using symbolic motifs (Gottdiener, 2001). By adopting theming in a marketing context, customers can be temporarily transported to another time and place, which they could not experience otherwise (Wood \& Muñoz, 2007). The core idea of theming is to "overwhelm the consumer with the omnipresence and omnipotence of a given brand identity” (Olson, 2004, p. 71). Based on engaging in a new setting, theming emphasizes the experience factor of an individual. Hence, theming focuses on selling branded services/experiences rather than selling branded products (Brakus, Schmitt, \& Zarantonello, 2009; Kozinets et al., 2002).

Theming aims at achieving several objectives. By crafting a strictly controlled, expected, and standardized environment (Hanningan, 1998), a themed setting can obviously entertain and educate a consumer about history, lifestyle, and culture (Wood \& Muñoz, 2007). These educational assets of theming raise issues about reality and authenticity. When a romanticized version of reality is often proposed, individuals tend to prefer the romanticized "hyper reality" to 
real life (Baudrillard, 1983; Eco, 1986). Solomon and English (1994) proposed that reality can be engineered, and thus, theming can be seen as a type of "reality engineering."

Muñoz et al. (2006) explained that theming is a multifaceted process. First, a structure has to match the physical design of the theme. The design, food, drink, and cultural artifacts must be carefully selected to match the desired representation of reality. Second, atmospheric elements must inspire a feeling of authenticity. Then, employees must conform with the chosen theme in their behavior and the selection of cultural symbols, such as music contributing to an appropriate atmosphere.

Theming has been used as a marketing technique in several contexts. In modern times, theming is predominant in most consumer lives, ranging from amusement parks to casinos, from malls to airports, and from restaurants to hotels (Muñoz et al., 2006). In the context of retail and manufacturing businesses, mindscape-related themes were determined as an opportunity for the future (Kozinets et al., 2002). Petkus Jr. (2002) introduced theming into the context of arts marketing. The results revealed that theming provides an opportunity to offer a consumer a more in-depth and robust art experience.

Other scholars have introduced theming into hospitality and tourism. Chang (2000) explored the theming of socio-spatial landscapes in the context of Little India/Singapore. The findings showed that the "themed landscape" had several negative consequences on the district, such as the decline of traditional businesses as well as the commodification and dimming of cultural identity. Theming was also investigated in the context of Asian theme parks (Wong \& Cheung, 1999). The still young industry of theme parks in Asia has potential for growth if theming is strategically undertaken. Other studies have dealt with theming in the context of the hotel industry. 
Several types of hotel theming have been recognized in literature. Prinz (2009) identified countryside, designed spaces, historical ties, luxury residences, mountain pastime, and urban and wellness hideouts as predominant hotel themes. Zins (1998) added tennis, golf, family, children, and slim and beauty hotels as categories that were predominant in Austria. Different themes have been determined as elements that triggered different kinds of expectations among guests (Zins, 1998).

Other scholars have divided hotel categories into cultural and non-cultural themes (Liu, 2005; Peng, 2008, Xiao et al., 2013, p. 135). Cultural themes refer to a country- or locationspecific set of traits, history, music, sports, cartoons, celebrities, or even high-tech and cartoons, such as seen in the "Hello Kitty" hotels. Non-cultural themes are generally nature-based, which can be animal, ocean, or desert-related hotel themes. Wood (2005, p. 403) showed several categories of themed roadside hotels in the United States, which attempted to "broaden one's horizons, even if only until morning.” Some of these themes refer to the past, other countries, or simply other geographical or natural environments.

Few empirical studies are directly or indirectly related to theme hotels. Oh, Fiore, and Jeong (2007) conducted a survey and identified that the aesthetic dimension of an experience for hotel guests is the most dominant factor in producing arousal, memory, overall equity, and satisfaction. Barreda and Bilgihan (2013) assayed a similar issue in the context of online hotel reviews. The results revealed that cleanliness and human contact were essential determinants of hotel experience satisfaction. Meanwhile, Alcántara-Alcover, Artacho-Ramírez, MartínezGuillamón, and Campos-Soriano (2013) compared the points of view on hotel experience of managers and consumers. The perception of end users on experiences was not always correctly understood by hotel managers. Related to theme hotels, Gross and Pullman (2012) determined 
that in practice, hotel employees often delivered a service experience in line with the objectives of the management. Employees required job experience, occupational norms, and context of delivery to be fully aligned with a theme. Unfortunately, empirical studies on hotel theming in China are very limited.

In China, hotel theming began with the opening of the Venice Crown Plaza Hotel in Shenzhen in 2001 (Xiao et al., 2013). This hotel proved to be a major success with customers, and thus, other hotel themes have emerged in the area, including the Spanish and Southeast Asian-themed hotel structures. Since then, other famous theme hotels have been established throughout China, and the number of theme hotels has increased from 140 in 2006 to over 400 in the subsequent three years (Xiao 2010; Xiao et al., 2013).

Thus far, the few studies that investigated the concept of hotel theming in China considered the perspectives of consumers, and the industry point of view seldom emerged (Xiao et al., 2013). Moreover, Western studies did not always connect to the uniqueness of the business environment in China as they mostly applied Western paradigms to an Asian context. Subsequently, a lack of understanding exists regarding the influencing factors and mechanisms of hotel theming, including what determines the decision of undertaking a hotel theme in China, what theming means in the Chinese cultural context, what possible inhibitors and facilitators are, and ultimately, what benefits are to be gained through theming efforts. To this end, this study attempts to mend the gap by examining the ideas of Chinese hotel practitioners on hotel theming in China.

\section{METHODOLOGY}

Literature on non-Western contexts is insufficient (Kong \& Cheung, 2009). Hence, qualitative approaches seem to be more suitable for the purpose of this study because such 
approaches answer the predetermined questions and allow new questions to emerge (Guion, Diehl \& McDonald, 2011). This study aims at understanding hotel theming in China from the views of practitioners (i.e., at understanding the perceived realities of participants by soliciting individual and collective constructions). Similar hermeneutic and dialectical issues are commonly solved through qualitative research (Denzin \& Lincoln, 2005).

This research particularly employed focus groups to investigate and to analyze the concept of hotel theming in China as perceived by industry practitioners. Involving experts in focus groups outside their working environment is deemed an effective tool of simulating reflections and constructive interaction (Gretzel, Fesenmaier, Formica, \& O’Leary, 2006). Reflection and construction are crucial in investigating the perception of participants, stimulate their out-of-the-box thinking, and subsequently reach the goals set for this study.

Denzin and Lincoln (2005) cited that a focus group is a quasi-formal or formal instance (e.g., conversations, group discussions, and negotiations) and an efficient qualitative method of producing data, which can seldom be obtained by interviewing individuals. Focus groups provide particularly powerful insights into norms and collective assumptions (Denzin \& Lincoln, 2005). Such technique equips the researcher with in-depth understanding of the topic discussed (Edmunds, 1999). Thus, focus groups have been widely used in tourism and hospitality research (e.g., Li, Lai, Harrill, Kline, \& Wang, 2011; Milman, 1993; Petrick, Li, \& Park, 2007; Welch, 1985).

In this study, the focus groups were conducted in a graduate-level hospitality and tourism marketing class offered in a preeminent Chinese university in East China to 42 hospitalityexperienced Chinese graduate students. Students of the class were mainly mid- to upper-level hotel managers, senior executives of hotel groups, and hotel owners, who were enrolled in an 
executive Master's program in hotel and tourism management. Seven out of the 42 students work in tourism or other related industries (e.g., travel agents, officials in tourism bureaus, real estate developers). The focus groups were part of the class exercises conducted when discussing marketing research. All students, except one who was absent in the class when the focus group was conducted, participated in this exercise. Participation in the discussion was voluntary, and no related grade of attendance was given.

Large focus groups are usually difficult to moderate and only allow limited opportunities for inputs from participants (Barbour \& Kitzinger, 1999). Hence, the authors decided to arrange relatively small focus group sessions to encourage more in-depth conversations. The 41 participants were randomly divided into seven groups, and all groups, except one, had six members.

Seven students who do not have hotel working experiences were asked to serve as moderators. These students were given a detailed bilingual focus group guideline developed by the research team. A short training session was conducted with these moderators by the class instructor, who is one of the authors of this paper. The training specifically aimed at conducting focus groups and highly emphasized on involving all participants in the discussion. The moderators were also reminded to use techniques/tactics discussed in class on marketing research, as well as in a research methods course they recently took. All focus groups were simultaneously conducted. All moderators started with a brief introduction on the background and purpose of the study, followed by nine questions regarding the understanding of hotel theming, examples of hotel themes in China, the advantages and disadvantages hotel theming may bring to a hotel, prospects and future directions of hotel theming in China, and so on. The focus group sessions 
lasted from 60 to 80 minutes, and all ended naturally. All sessions were audio taped and later transcribed in Chinese.

Out of the 41 participants, the average working experience declared in the Chinese hotel industry was 13 years, which ranged from a minimum stated experience of 2 years to a maximum of 28 years. The average age of the participants was 35 years, which ranged from a minimum of 24 to a maximum of 50 years. Seventeen of the focus group participants are hotel or hotel chain general managers, presidents, directors, or chairmen, while 21 are vice general managers or departmental managers. Meanwhile, the others work as lecturers, officers, and secretaries. Out of the 41 participants, 14 were female, while the remaining 27 were male.

Holly (1999) suggested that researchers must enumerate the similarities and differences introduced by participants and tie the findings back to the overall research objectives of the study to best report the findings of focus groups. In this study, the results were coded according to the most significant themes, which have emerged in relation to hotel theming in China and the general research questions asked. Frequency counts could be possibly misleading because individual speakers could not always be identified from the tape during the transcribing process (Krueger, 1998). The contents of different focus groups were compared in terms of themes and not by how frequent a comment was made. This approach has proven successful in previous studies that have applied focus group techniques in similar contexts (e.g., Hung, 2013).

The transcribed data were coded by one of the authors with the help of the qualitative research software NVivo. Coding is usually inductive and deductive (Hennink, Hutter, \& Bailey, 2011). Inductive codes refer to themes directly raised by the respondents, whereas deductive codes emerge through previously established theory. The data were allowed to "speak for itself," and themes were primarily identified by adopting inductive coding because the nature of this 
study was largely exploratory. The identified themes were independently verified by another researcher. The four analytical dimensions emerged from the data are "the current state of hotel theming in China," "facilitators for hotel theming in China," "inhibitors for hotel theming in China," and "the future development of theming in China."

\section{FINDINGS}

The participants identified the current state of hotel theming in China, facilitators, inhibitors, and predictions for the future development of hotel theming in China.

\section{Current state of hotel theming in China}

Participants explained that most Chinese theme hotels are located around scenic sites and adopted fitting themes. Accordingly, cultural theming is considered an approach that is still misunderstood and not widely applied by most Chinese hoteliers. Most hoteliers only understand theming based on tangible assets, such as facilities, decoration, and clothing, and consequently, neglect the possibility of intangible theming. This finding also caused a copycat movement, with one respondent noticing "four love theme hotels in the same small city." The tangible assets of theming are easy to establish, and even easier to copy. This finding indicates less competitive advantage. A chess-themed hotel in China, for example, was mentioned to have heavily focused on the interior design, but was unable to fit its employees into the theme. Guests easily got bored because the "waitresses have no idea about how to even play chess." Hotel guests might have chosen to stay in this particular hotel because of their interest in this game.

Respondents reported few successful stories of theme hotels in China. A boutique hotel in Shenzhen chose a Buddhist theme and made "every employee and the manager dress like monks." Participants stated that real monks were in the hotel, and guests lived in the genuine environment of a Buddhist temple. In spite of the luxurious structure, the hotel chose to offer "no TV, no 
Internet, and no Air Conditioning." Employees of the hotel were reported to be "living like nuns and not even wanting to get married if they keep on working there.” The majority of the other hotels only displayed a themed outlook and were often less successful. However, this fully themed hotel was said to have a high profit rate.

Other success stories are related to foreign-themed hotels in China, including the visible enthusiasm for the planned Disney resort or the Armani hotel in Shanghai. Foreign themed hotels are usually keen on the intangible assets of theming, in which the guests have already formed an image in their minds when they arrive. Participants mentioned that Chinese tourists particularly favor futuristic and foreign-themed hotels because these themes inspire their trust. Some hotels have created fusion themes, such as combining traditional Chinese themes with French influences in a hotel in Hangzhou. This theme hotel was noted as well received. International guests often prefer retro-style, more adventurous, and traditional Chinese culture themes. One participant summed up the idea by stating, "Foreigners like the past, Chinese like the future. Why do we travel? We travel to see something different. This is what it is all about.” A similar division was highlighted between Chinese tourists from the countryside and tourists from the cities. More modern themes are well received by tourists from rural places, whereas urban residents often prefer a more nostalgic and simpler design. One case in China was mentioned in which "a woman rented an entire village to attract people from urban areas to enjoy the nostalgia of rural life."

Participants reported that most Chinese hotels have themes according to their geographical location and specific local culture of the area. These two assets are generally well received because they are interesting even for repeat visitors. The majority of the participants 
believe that theming mainly refers to the furniture and appearance of the hotel, in which a more inclusive concept, including more intangible assets, is often ignored or misunderstood.

\section{Facilitators of hotel theming in China}

The Chinese hotel market is becoming more competitive. Thus, innovative practices, such as hotel theming, can be considered as one option to gain competitive advantage. Hotels must observe the eventual facilitators of hotel theming in the country's particular context as an essential step in considering whether to adopt a theme. Four important facilitators have been identified based on the comments of the participants during the focus group sessions (Figure 1). The facilitators are as follows: (1) differentiation by adopting various local Chinese culture for hotel themes because of several heterogeneous local religious, ethnic, regional, and/or historical traits; the possibility of combining cultural themes with local food, music, colors and decorations, and local staff "living the local culture," adding to the authenticity of a theme; (2) differentiation by using various local geographical features for hotel themes through several unique geographical features within the country, and the possibility of emphasizing the unique location

of the hotel through a theme; (3) a shift in the tourist market from government/business to leisure tourists through the emerging niche markets and a growing domestic market with more interest in leisure travel; and (4) government support in terms of tax and land benefits through themes aligned with government interests. 


\section{Figure 1}

Facilitators of hotel theming in China

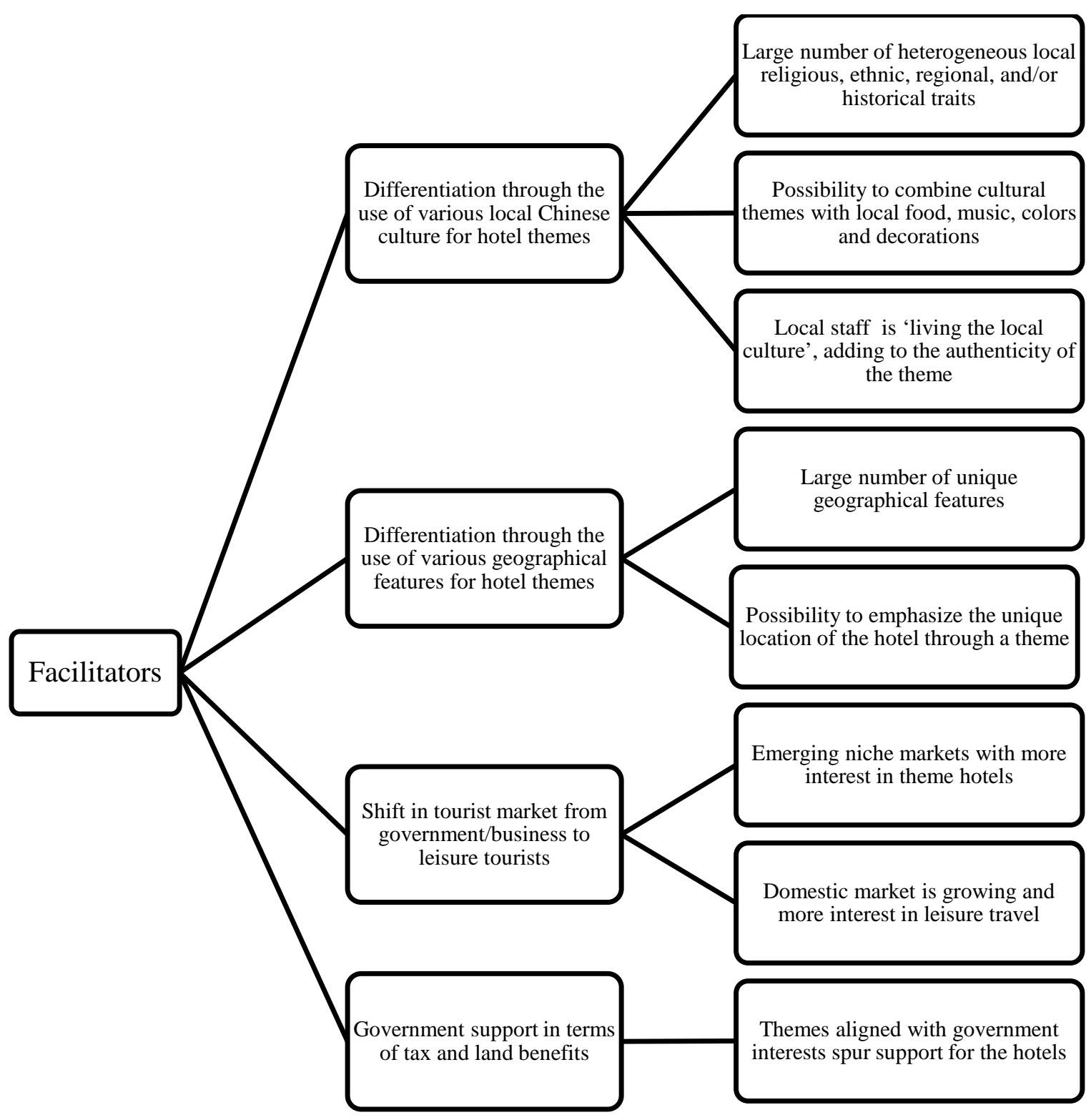

The majority of the participants agreed that China has numerous and highly valuable resources, which can facilitate hotel theming. Chinese culture is considered a particularly valuable asset. Moreover, different locations in China display extraordinarily diverse local cultures, which can be incorporated into hotel themes. A respondent suggested differentiating 
hotels through specific "religious, ethnic, regional, and historical traits of a particular area." The combination of these traits with particular food, music, colors, and decorations was recommended to match the chosen cultural theme. Several successful culture-themed hotels in China, such as the Tang Dynasty hotel in Xi'an and the traditionally theme hotels in Shanxi province, were mentioned. Nonetheless, the participants agreed that to date, most Chinese hoteliers have not recognized the enormous potential of combining local culture with hotel themes. Ironically, a participant mentioned, "Chinese theme hotels have emerged in Indonesia, Egypt, and other countries to meet the need of the growing number of Chinese tourists," whereas in China, the potential use of local Chinese culture for theming has not been yet fully realized. Theming a hotel with local culture will not necessarily appeal only to a small target group as it could very well attract many potential guests. If locals are hired as staff, they will also represent the local culture with no need for cultural adaptation or extra training.

The respondents suggested themes based on certain scenic and geographical assets of China. A hotel in Sanya was mentioned as being themed on a "bird's nest, overlooking the bay like a bird sitting on a stone." When a theme is location specific, it becomes hard to duplicate, and other places within the country cannot offer the same product to tourists. Subsequently " $a$ Suzhou Garden will not be built in Macau because it just would not fit the scene." Location is perceived as a main reason why guests choose a certain hotel (Yang, Wong, \& Wang, 2012). Thus, a theme based on such an asset could place the hotel into a favorable position, while underlining its uniqueness of being positioned in a specific context. The participants suggested that Chinese hotels might take advantage of the country's cultural and geographical variety, and develop specific themes based on either cultural or geographical factors. The participants also mentioned that man-made attractions within the vicinity of a hotel are possible facilitators of 
theming. For instance, a hotel in "overseas Chinese Town in Shenzhen uses Spanish culture as a theme. The reason therefore is that it is close to the "Window of the World" theme park, and guests visiting the area are likely to be interested in foreign cultures.”

A shift in the tourist market structure was also mentioned as a major facilitator of hotel theming in China. In the past, the majority of the Chinese hotels were reserved for business travelers or government officials, in which neither segment was particularly interested in theme hotels. The participants indicated that niche markets and leisure tourists are generally not perceived to warrant major hotel turnovers because of their limited number. Hence, "with the new change of government leaders, government sponsored public consumption has been limited, and hotels targeting governmental officials will be negatively affected." Moreover, the participants suggested that China's National Congress of China had predicted that the domestic individual disposable income will double, and thus, leisure consumption will increase. Accordingly, some hotels that have been targeting business tourists and government officials may switch their focus to target the new and younger niche markets with hotel themes.

The participants stated that the Chinese government should facilitate hotel theming if the right theme is chosen. In general, culture-themed hotels were often mentioned as gaining government support in terms of tax benefits and accessibility to land. The government was described as being concerned about the "face" of a city by encouraging certain themes, while banning sex or gambling-based hotels as both activities are illegal in China. If the chosen theme is within government interests and promotes specific geographical areas or cultural traits, which are promoted by the government, hoteliers can gain benefits in terms of investment, tax, or favorable locations. One respondent gave the example of a hotel in Ningbo, in which "the local government was eager to transform a historic site of the Ming Dynasty into a famous scenic spot. 
Now, a hotel has signed a contract with the local government to change this heritage site into a themed five star hotel. So the theme hotel is not only promoting the hotel, but also the local culture." Hotel themes are also used to enhance relationships with the government. A participant even asserted that some hotels are built specifically to relate to government institutions. Hence, "some businessmen build hotels only to get in touch with government leaders, as they welcome high-profile guests in their high-class hotel."

Inhibitors of hotel theming in China

Apart from the facilitators of hotel theming, identifying and understanding the related inhibitors of theming in the context of China are also necessary. The focus group participants raised two main issues that reflect the uniqueness of the Chinese hotel and tourist market (Figure 2). The issues are (1) Chinese business culture with its preference for "low-risk" investment, short-term profits, and the usage of hotels for real estate and other non lodging-related activities; and (2) domestic tourists travel culture, which is generally less adventurous than its Western counterparts and has difficulty in accepting "edgy" themes. 
Figure 2

Inhibitors of hotel theming in China

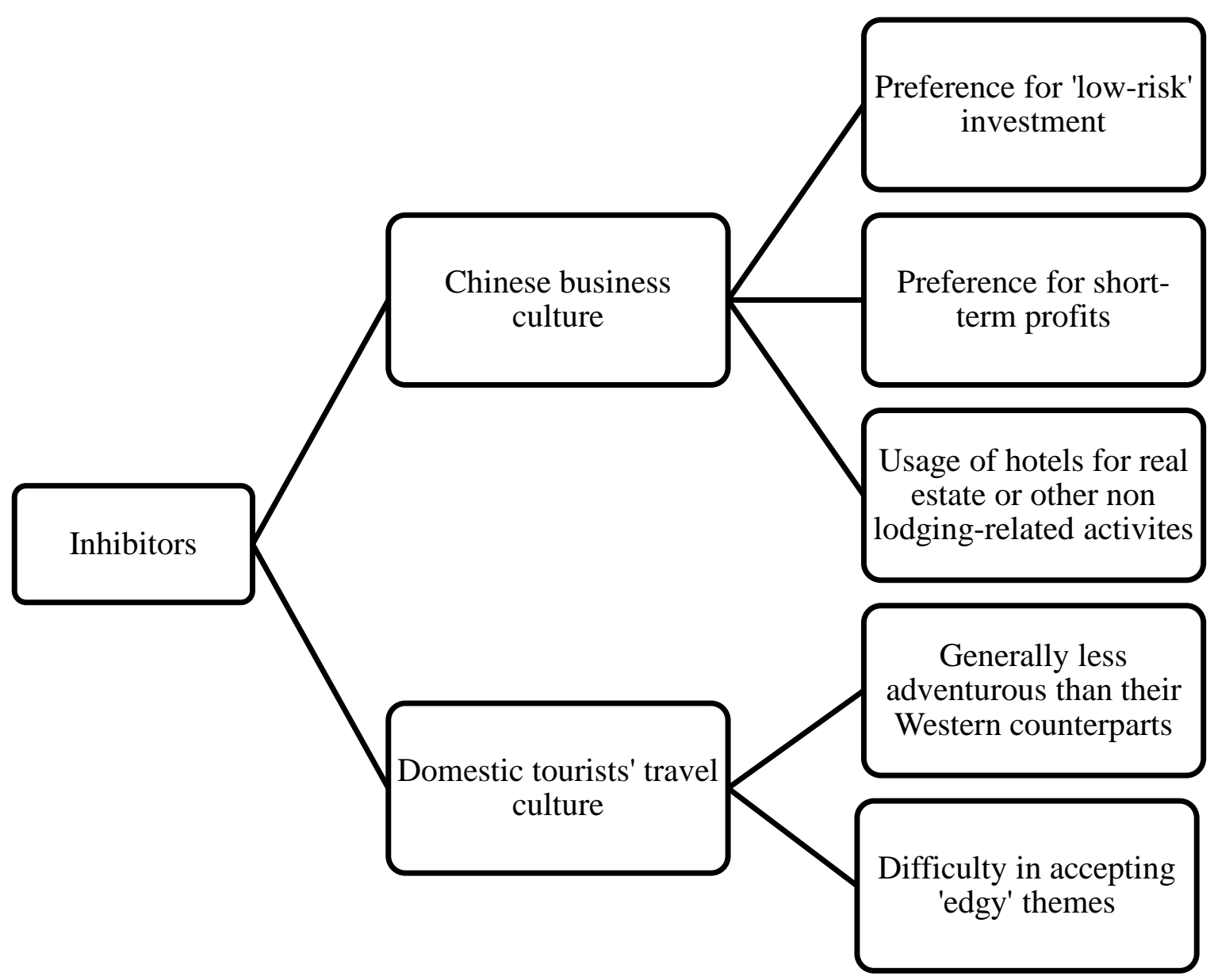

The business culture of China was mentioned to have particular traits that differ from most other countries. Hotel theming is a so-called "high risk" business that requires long-term investment and precise targeting of a certain niche market. Currently, for most Chinese hotels, business tourists still outnumber leisure tourists. Thus, choosing a theme entails targeting a different market base. The participants mentioned that most Chinese investors are short-term oriented and look for maximum profit in a short period. Meanwhile, "the return of investment for 
theme hotels takes longer than that of conventional hotels. Nowadays, however, Chinese businessmen lack patience.” The idea of giving up immediate profit for long-term gain seem unreasonable to many hoteliers. Many businessmen enter the hotel business only for the real estate value of the structure (i.e., for reselling the property at a higher price after several years). One participant stated, "Chinese hotel investment is not always fully legal. Some investors do not operate for profits, but for real estate or money laundering. I have worked in several hotels, which cannot make profits, but the bosses keep them open for other reasons." In this case, investment in a hotel theme is not an option because this type of profit is not the focus of the owners.

The participants mentioned that domestic Chinese tourists are less adventurous than foreign tourists. Hotels equipped with creative themes, such as "sleeping on trees, capsule hotels, or prison hotels," are well received by overseas tourists. Meanwhile, most Chinese still prefer traditional cultural themes, typical hotel comforts, and less exotic environments. Therefore, the current preferences of Chinese tourists might be an inhibitor to develop a hotel theme, which is too edgy. Hoteliers should consider this matter into account. Nonetheless, a respondent added that this situation might change as China develops.

Themed hotels in China are often not well planned. A participant stated, "one of my relatives opened a cartoon-themed hotel in Hangzhou. The location of the hotel is good as it is close to the city center. However, after introducing the cartoon theme, the hotel experienced a decline of guests. The cause of this decline is that the majority of the previous guests were businessmen who thought that this hotel was now particularly designed for children.” This occurrence could be due to a simple mismatch between the product and market. However, Chinese guests were considered to possess little tolerance to such changes. The participants 
mentioned that some market segments would inevitably be excluded with whatever theme was chosen. This observation implies that the theme of a hotel must be well planned and adequately chosen for the specific case of each individual hotel.

\section{Future of hotel theming in China}

The participants provided their predictions regarding the future development of hotel theming in China. Considering the trends and developments of the industry is crucial for hotel practitioners when choosing a theme. Based on the focus group discussions, seven predictions for future development of hotel theming in China have been made (Figure 3). First, competition among theme hotels augments as the number of theme hotels increases, and hotels will look for competitive advantages. Second, superficially themed hotels failed as they are easy to copy, and guests are becoming more sophisticated. Third, the sophistication of guests could lead to the success of carefully thought-outappropriately themed hotels as these hotels emphasize their unique cultural or geographical position, which are hard to imitate. Fourth, the development of specific government regulations for theme hotels is needed because the competition among these hotels can get unruly. Hence, low quality theme hotels will dominate the market. Fifth, theme hotels are likely to introduce globally the Chinese culture because of a growing worldwide interest in such culture. Familiarity with Chinese culture can help domestic hotels develop cultural themes as Chinese hotels are becoming more internationally competitive. Sixth, the success of themes related to the past and current Chinese culture resulted from the preference of the majority of foreign guests, and this trend is also growing for urban Chinese residents. Seventh, the success of futuristic and foreign culture themes will be likely because most Chinese guests prefer these themes. This trend is likely to persist especially among the rural population in the near future. 
Figure 3

\section{Predictions for future development of hotel theming in China}

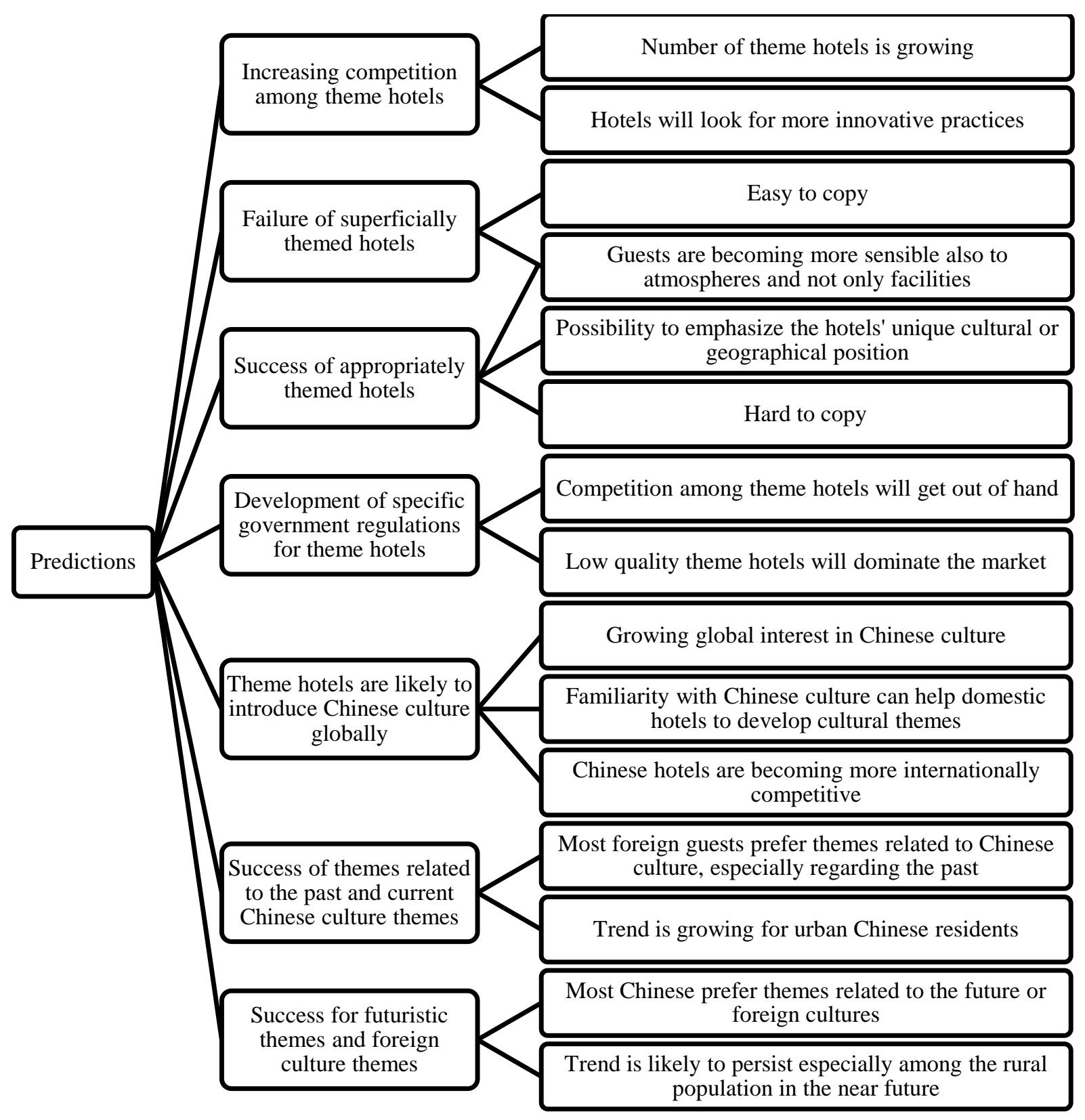


Competition is widely considered a top concern of Chinese hoteliers. The participants shared their worries on how the increasing number of hotels will create an even more challenging business environment. Theming was seen as a tool in providing good possibilities for hotels to create a future competitive advantage. Hotel theming in China is still in its infancy, but is rapidly growing. Thus, theme hotels were seen as "probably facing high levels of competition in two to three years." This situation will eventually drive some theme hotels out of the market, and force them to choose another business strategy, or else, they will fail.

The respondents also expressed their opinions regarding the quality of current themes in Chinese hotels. They stated that superficially theme hotels will most likely "disappear due to high levels of competition," and proper theming is a good means of overcoming the Chinese market. Accordingly, this condition denotes that Chinese hotels must focus on intangible assets, including adequate representation of culture and creation of an authentic atmosphere for their guests. This kind of theming requires more input from the management in development and implementation, and is often more location specific, which means that it is harder to be replicated by other hotels. Most of today's hoteliers lack the understanding or financial resources to execute properly this kind of theming. Accordingly, the practitioners believe that the hotels that properly adopt theming have a higher chance of being successful.

One participant suggested that the competition among theme hotels would become unruly if more investors become involved. Therefore, the government must be included in the business by guiding and restricting theme hotels. Otherwise, considerable low quality theme hotels will emerge in the Chinese market, and ultimately discourage tourists to opt for such accommodations. A practitioner affirmed this observation because "copying is a serious problem in China, and not limited only to theme hotels. It is easy to buy a certain theming furniture, but 
difficult to determine the untouchable part of a culture. Thus, to avoid being copied, a theme hotel must address its untouchable part.”

The participants suggested that themes based on the past and on the future would have a chance to succeed. Foreign tourists currently prefer themes related to the past, whereas Chinese tourists prefer themes related to the future. Both markets are believed to persist, especially with urban residents of China growing more nostalgic for the past, and opening the doors to more historically themed hotels in the future. The respondents also stated that usually "international guests prefer Chinese themes, whereas Chinese guests prefer foreign themes.” This observation presents future possibilities for both theming choices.

Hotel theming could also be a valuable asset to succeed in foreign markets and to introduce Chinese culture globally. Presumably, domestic hotels are more capable of developing and promoting a given Chinese cultural theme than foreign chains. For foreigners who are "interested in Chinese culture and history," Chinese hotels can address these needs by creating proper themes. However, a question arises if promoting culture and financial benefits can always go together. The government might be more interested in culture, while private investors might focus on gaining profits.

Overall, an argument was raised in that "theme hotels in China are still in their infancy, but have great potential to improve." The participants generally agreed that considerable theme hotels would enter the Chinese market in the following years. In particular, "the major cities and coastal cities will soon adopt theming as the competition in these areas is already intense. The Western and inland part of China will probably adopt theming practices within the next five or 10 years." Business tourists are still believed to be the focus of most hotels. Nonetheless, even the leisure travel market was suggested to grow highly competitive, and hotel theming has been 
accepted by the participants as a valuable strategy if undertaken with caution. Moreover, the respondents proposed that many of the emerging theme hotels are likely to fail if theming is not properly adopted. Finally, the participants concluded, "for theming in China to succeed a good master plan for a hotel is necessary."

\section{DISCUSSION AND IMPLICATIONS}

Modern customers look for experiences rather than merely goods or services (Pine \& Gilmore, 2011). Accordingly, experience-marketing techniques, such as theming, can have a decisive influence on the hotel industry. This condition is reinforced by the fact that tourism products heavily rely on the experience factors of their consumers (Kozinets et al., 2002). Nonetheless, hotel theming has been identified as a practice that requires both skill and investment.

Constructing a coherent theme, which totally immerses the consumer into the desired brand identity and values, is crucial (Olson, 2004). This construction refers not only to the physical design of the hotel, but also to the need to align cultural symbols and hotel employees to the desired representation of reality (Muñoz et al., 2006). The same core values of the chosen theme must also be observed in every marketing effort of the hotel (Petkus Jr., 2004). If theming is superficially approached or in neglect of its potential consequences, it might as well turn out to be more counterproductive than beneficial (Chang, 2000).

The nature of theming is highly complex. However, several inhibitors have been identified by the participants, in which hotel theming was generally seen as a good tool of enhancing hotel competitiveness in the highly challenging Chinese hotel market. By strategically adopting a theme, Chinese hotels can cater to foreign experience seekers and the growing domestic markets, and avoid being imitated by other hotels. 
The success of the growth of the domestic leisure market has been identified with the possible success of theming practice and by considering that entertainment is an important factor to the success of a theme (Kozinets et al., 2002). The participants have noticed several differences among Chinese and Western tourists. This observation is important for hoteliers because hotel theming extensively relies on the experiences of guests in themed settings (Wood \& Muñoz, 2007). First, domestic Chinese tourists were described as generally less adventurous in their choice of hotel themes. Therefore, edgy themes, such as "sleeping on trees" or "box hotels," must mainly target foreign tourists and not point exclusively to domestic tourists. Moreover, hotels with themes appealing only to certain niche markets must be aware of the fact that the size of their target market will be smaller and be clearly defined.

The preference for futuristic themes among Chinese tourists has been mentioned. Postmodernism has raised a feeling of nostalgia and loss of authenticity among many Westerners (Goulding, 2000). However, this issue was not perceived as a major concern in China. The participants cited that majority of the Chinese tourists prefer to look toward the future, which suggests the possibility of technology-based or futuristic themes. Moreover, cultural fusion themes with traditional Chinese elements and foreign influences were reported to be successful. This theme has also been suggested in an earlier study by Ou (2003). Hotels of such themes would be able to provide domestic tourists with the desired level of comfort and an exciting sense of living in the future. The hotel practitioners have suggested that the Chinese market must be carefully monitored because the desire for more original themes has been increasing in other countries as the relevant disposable income has increased. Changes in the preferences of customers might occur in the future as more mature markets have shown more tolerance for innovative themes and because of the economic growth in China. 
The choice of a hotel theme, which is at least partially linked to a specific local culture and location, was identified as adequate for hotels in China. First, the correct application of a culturally themed hotel has been reported to be scarce in China. Considerably a large number of tourists can be interested in a cultural theme. However, many hoteliers appear to interpret hotel theming only as visual symbols reoccurring in a hotel's “servicescape” (Bitner, 1992). The participants mentioned that interpretation often results in the lack of an authentic atmosphere and ultimately in the delusion of guests. Muñoz et al. (2006) emphasized that atmospheric assets, such as the correct choice of cultural connotations, and the conformity of employees are needed for the theme to succeed. The short supply of qualified labor for the Chinese hotel industry (Hung, 2013) will be a major challenge for a theme hotel. Nonetheless, by choosing an indigenous cultural theme and by hiring local employees, the hotel will not have to go through the process of acculturating its employees to the chosen theme. To some extent, the employees may simply be themselves. This strategy might enhance the sense of place and authenticity of the guest as well as educate them about the local culture (Wood \& Muñoz, 2007). These effects will create a more natural and less "engineered” feeling.

The respondents suggested that hotels could act as cultural ambassadors and contribute to sustainable tourism development by choosing a local culture theme. By hiring local staff, employees would be able to "live the local culture" without undergoing excessive training. Thus, hotel theming in the context of China has the potential to alleviate poverty and to spur the development of local tourism by hiring local staff as part of the brand identity.

Local culture in general is a tool, which can be integrated in both development and conservation (Cohn, 1988). By adopting a local cultural theme, Chinese hotels can contribute to preserving the local cultural heritage. In the context of China, the active involvement of local 
cultures into tourism initiatives has proven successful in preserving minority traditions and reaffirming ethnic identities (Yang, 2013). By cautiously opting for hotel themes and cultural sensitivity, theming has the potential to preserve and reinforce local Chinese cultures and identities.

In terms of sustainability, the use of local materials to develop a hotel theme can also be beneficial. From the demand side, tourists perceive a higher level of authenticity if local materials are used in a destination (Torabian \& Arai, 2013). From the supply side, the purchase of goods from local businesses has the potential to be an additional tool of increasing local income and conserving local traditions and identity. Subsequently, hotel theming has the potential to benefit a destination in both economic and sustainable terms.

By focusing on a location and its adjacent culture, the chosen hotel theme might be less subjected to copying by other Chinese hotels. The participants have mentioned that the wide array of cultural and geographical features within China allows the choice of several diverse and location-specific themes. By incorporating the relevant local atmospheric assets, employees, and traditions, hotels in other locations will not be able to copy the experiential factors of the theme. This condition will ultimately be cost-efficient, educational, and authentic. Moreover, the participants have presented that locally inspired themes might be the only choice that might appeal to both foreign and domestic guests. Furthermore, more mainstream themes that are culturally or historically based might overcome certain traits of Chinese investors. Some of these traits include the avoidance of risk and the preference for short-term profits by attracting a larger target market.

Finally, the Chinese government is considered a key element for the success of Chinese theme hotels. The participants have mentioned that less government officials are traveling these 
days because of the spending austerity measures self-imposed by the Chinese government. However, the government authorities have increased their support for domestic hotels. Several instances have been mentioned, in which local governments have given favorable tax conditions and permits to access favorable locations to theme hotels because of their chosen Chinese cultural theme. Hung (2013) stated that the important role of the Chinese government in the future of the hotel industry will persist during the coming years. Hence, Chinese hoteliers willing to pursue a theming strategy must follow government regulations and consider possible government initiatives, which might benefit their specific choice.

Generally, the number of theme hotels is expected to grow rapidly in the near future. This prediction is consistent with the over 300\% increase of theme hotels in China during the last decade (Xiao, X., 2010; Xiao, Q. et al., 2013). Although hotel theming is still a relatively new concept, the participants have indicated the possibility of fierce competition among theme hotels. To stay competitive, hotels must carefully choose their theme and be strategic in its application. Government regulations and guidance on the number and quality of theme hotels are needed to help their survival in the Chinese market.

The findings of this study lead to several practical implications for hotel managers and practitioners in general. First, the respondents have suggested that a difference among Chinese and Western guests exists when it comes to hotel theming. A thorough market research on the target market must be done in advance because hotel themes must be carefully planned, and the amendments after the initial opening are usually very costly (Xiao, Q. et al., 2013). If guests are likely to be domestic tourists, a futuristic or foreign theme can be an effective option, while for most Western tourists a traditional Chinese cultural theme is more likely to be effective. 
If a hotel theme related to local culture is opted for, hotel managers could consider using local materials and hiring local staff to (1) contribute to the authenticity of the theme, and (2) to allocate fewer resources for recruiting employees and providing tangible assets of the theme (e.g., staff uniforms, furniture, offered activities). Many Chinese hotels are struggling with lack of resources (Pine \& Qi, 2004). Thus, the allocation of fewer resources for recruiting employees could allow managers to allocate more funds to the improvement of service quality, which must be particularly consistent in theme hotels (Xiao, Q. et al., 2013). Moreover, additional funds can be used to develop core competence and knowledge, and to generate and sustain competitive advantage (Horsburgh, 1991). Such elements can help in developing an appropriately themed hotel that, according to the participants, is more likely to survive and find success in the competitive Chinese market.

Finally, the respondents have suggested that the Chinese government can occasionally offer tax and land benefits if themes are aligned with government interests, and that in the future, specific government regulations for theme hotels might be developed. This phenomenon is particularly apparent in China (Pine \& Qi, 2004) considering that government officials are generally important in the hotel industry (Tisdell \& Wen, 1991). To the knowledge of the authors, no specific government regulations for theme hotels have been released to date. However, the respondents have suggested that hotel practitioners must look for in-depth information and opportunities regarding government regulations.

\section{CONCLUSION}

In the future, cutthroat competition and the new political environment in China's hotel market will force Chinese hoteliers to study original practices and consider hotel theming. Based 
on this development, focus groups among Chinese hotel practitioners were conducted with emphasis on hotel theming in the Chinese context. The possible facilitators and inhibitors as well as the future development of hotel theming were identified in this study.

Several specific traits of the Chinese hotel market, which must be considered when opening a theme hotel in China, have emerged. Consistent with the previous study of Kong and Cheung (2009), Western paradigms were identified to be not always applicable to this specific context. The particular cultural and political situations in China have raised issues and possibilities for successful hotel theming. Based on this information, Chinese hotel practitioners and foreign investors can identify specific threats and opportunities, which will influence their choice of hotel themes.

This study has several limitations. First, the focus group participants were recruited by using a convenient sampling technique. All participants were highly knowledgeable about the Chinese hotel industry. However, a more representative sample of Chinese hotel executives would likely generate more generalizable findings. Alternatively, a panel of industry veterans specialized in hotel theming (e.g., general managers or owners of theme hotels) could provide some "insiders' insights" through direct experiences and observations. Second, although several facilitators and inhibitors for successful hotel theming in China have been identified, recommendations for hotel practitioners have not been prioritized. This study was based on the perception of hotel practitioners. Thus, government authorities have not been consulted regarding possible regulations or official statements. Meanwhile, the focus group sessions being not professionally moderated presents another limitation. The quality of answers could have been improved, had more laddering questions asked, and the moderators "pushed" a bit further. Finally, the comparison of hotel themes in China and in other countries has mostly been based on 
secondary data, such as journal articles. While the participants are highly experienced in the Chinese context, they might not be equally aware of the situation in other countries.

Despite the limitations, this study presents fertile ground for future research. First, scholars could approach the topic of hotel theming in China from a policy perspective by investigating specific regulations and their implications for hotel theming. Second, the issue of authenticity perception of Chinese guests regarding hotel themes was raised several times and was suggested to be substantially different from the Western perspectives (i.e., Westerners often associate authenticity with nostalgia for the past), which were suggested not to be the case for most Chinese people. Future studies could investigate which themes are perceived as authentic by Chinese guests, and if this concept is important in this specific context. Further, as indicated, theming in a hotel is more than a branding or decorating endeavor, and may tackle various aspects of the hotel's product design, service delivery, and management strategies.

Fundamentally, theming could very well extend the basic functions and missions of hotels, and make hotels a multi-functional establishment not only for accommodations or meals, but also for recreation, education, and entertainments. The managerial, marketing, and human resource implications of this change warrants further research attention. Lastly, further studies could investigate the link between hotel performance and the choice of a theme in the Chinese context. The results might also be compared with other countries to understand the added value of hotel theming globally and on a broader scale. Also, salient points which have emerged from this study could be further investigated through similar methods with frequency counts in further research. 


\section{REFERENCES}

Alcántara-Alcover, E., Artacho-Ramírez, M. Á., Martínez-Guillamón, N., \& Campos-Soriano, N. (2013). Purpose of stay and willingness to stay as dimensions to identify and evaluate hotel experiences. International Journal of Hospitality Management, 33, 357-365.

Barbour, R., \& Kitzinger, J. (1999). Developing focus group research: Politics. Theory and Practice.

Barreda, A., \& Bilgihan, A. (2013) An analysis of user-generated content for hotel experiences. Journal of Hospitality and Tourism Technology, 4(3), 263-280.

Baudrillard, J. (1983). Simulations. Semiotext, New York.

Bitner, M. (1992). Servicescapes: The Impact of Physical Surroundings on Customers and Employees. Journal of Marketing, 56(2), 57-71.

Brakus, J. J., Schmitt, B. H., \& Zarantonello, L. (2009). Brand Experience: What Is It? How Is It Measured? Does It Affect Loyalty? Journal of Marketing, 73(3), 52-68.

Carù A., \& Cova B. (2003), Approche empirique de l'immersion dans l'expérience de consommation: les opérations d'appropriation, Recherche et Applications en Marketing, 18(2), 47-65.

Carù, A., \& Cova, B. (Eds.). (2007). Consuming Experience. Routledge.

Chan, B., \& Yeung, S. (2009). Hotel Development in China: The Hoteliers' Perspective: 酒店从 业员对中国酒店业发展的看法. Journal of China Tourism Research, 5(2), 210-223.

Chang, T. C. (2000). Theming Cities, Taming Places: Insights from Singapore. Geografiska Annaler: Series B, Human Geography,, 82, 35-54.

Cohn, J. P. (1988). Culture and conservation: a greater sensitivity to local culture could increase the success of both conservation and development projects. BioScience, 38(7), 450-453. 
Denzin, N. K., \& Lincoln, Y. S. (Eds.). (2005). The Sage handbook of qualitative research. Sage Publications, Incorporated.

Eco, U. (1986). Travels in hyper reality: Essays. NY: Harcourt Brace \& Co.

Edmunds, H. (1999). The focus group research handbook. Chicago: NTC Business Books.

Giaccari, F. (2003). Attività economica e le aziende. In N. Di Cagno, S. Adamo, \& F. Giaccari (Eds.) Lezioni di Economia Aziendale, (pp. 11-38). Bari, IT: Cacucci.

Glazer, R. (1991). Marketing in an Information-Intensive Environment: Strategic Implications of Knowledge as an Asset. Journal of Marketing, 55(4), 1-19.

Gottdiener, M. (2001). The theming of America: American dreams, media fantasies, and themed environments. Westview Press.

Goulding, C. (2000). The commodification of the past, postmodern pastiche, and the search for authentic experiences at contemporary heritage attractions. European Journal of Marketing, 34(7), 835-853.

Gretzel, U., Fesenmaier, D. R., Formica, S., \& O’Leary, J. T. (2006). Searching for the future: Challenges faced by destination marketing organizations. Journal of Travel Research, 45(2), 116-126.

Gross, M. A., \& Pullman, M. (2012). Playing their roles: Experiential design concepts applied in complex services. Journal of Management Inquiry, 21(1), 43-59.

Gu, H., Ryan, C., \& Yu, L. (2012). The changing structure of the Chinese hotel industry: 19802012. Tourism Management Perspectives, 4, 56-63.

Guion, L. A., Diehl, D. C., \& McDonald, D. (2011). Conducting an in-depth interview. U.S. Department of Agriculture, UF/IFAS Extension Service, University of Florida. Retrieved March 30, 2014 from http://edis.ifas.ufl.edu/fy393 
Hannigan, J. (1998). Fantasy city: Pleasure and Profit in the Postmodern Metropolis. Routledge.

Hennink, M., Hutter, I., \& Bailey, A. (2011). Qualitative Research Methods. Sage.

Holly, E. (1999). The focus group research handbook. Lincolnwood, IL: NTC Business Books and American Marketing Association.

Horsburgh, S. (1991). Resources in the international hotel industry: A framework for analysis, International Journal of Contemporary Hospitality Management, 3(4), 30-36.

Hung, K. (2013). Understanding China's Hotel Industry: A SWOT Analysis 中国酒店业的 SWOT 分析. Journal of China Tourism Research, 9(1), 81-93.

Kong, H., \& Cheung, C. (2009). Hotel development in China: A review of the English language literature. International Journal of Contemporary Hospitality Management, 21(3), 341355.

Kong, S. H. (2006). An empirical investigation of mainland Chinese organizational ideology. Asian Business \& Management, 5(3), 357-378.

Kozinets, R. V., Sherry, J. F., DeBerry-Spence, B., Duhachek, A., Nuttavuthisit, K., \& Storm, D. (2002). Themed flagship brand stores in the new millennium: theory, practice, prospects. Journal of Retailing, 78(1), 17-29.

Krueger, R. A. (1998). The focus group kit 6: Analyzing \& reporting focus group results. Thousand Oaks, CA, US: Sage Publications.

Li, X., \& Petrick, J. F. (2008). Tourism marketing in an era of paradigm shift. Journal of Travel Research, 46(3), 235-244.

Li, X., Lai, C., Harrill, R., Kline, S., \& Wang, L. (2011). When East meets West: An exploratory study on Chinese outbound tourists' travel expectations. Tourism Management, 32(4), 741-749. 
Liu, W. (2005). The building and management of theme hotels in China - A case study on Jingchuan Hotel in Chengdu (Unpublished master's thesis). Sichuan University, Chengdu, China.

Milman, A. (1993). Maximizing the value of focus group research: qualitative analysis of consumer's destination choice. Journal of Travel Research, 32(2), 61-64.

Muñoz, C. L., Wood, N. T., \& Solomon, M. R. (2006). Real or blarney? A cross-cultural investigation of the perceived authenticity of Irish pubs. Journal of Consumer Behaviour, 5(3), 222-234.

Oh, H., Fiore, A. M., \& Jeong, M. (2007). Measuring experience economy concepts: tourism applications. Journal of Travel Research, 46, 119-131.

Olson, S. R. (2004). The Extensions of Synergy: Product Placement Through Theming and Environmental Simulacra Journal of Promotion Management, 10(1-2), 65-87.

Ou, L. (2003). Reflections on cultural integration of China's theme hotels. Tourism Science, 13(3).

Peng, X. (2006). A study on theme hotels based on customer experience (Unpublished master's thesis). Zhejiang University, Hangzhou, China.

Petkus Jr, E. (2004). Enhancing the application of experiential marketing in the arts. International Journal of Nonprofit and Voluntary Sector Marketing, 9(1), 49-56.

Petrick, J., Li, X., \& Park, S. (2007). Cruise passengers' decision-making processes. Journal of Travel \& Tourism Marketing, 23(1), 1-14.

Pine, B. J. II, \& Gilmore, J. H. (1998). Welcome to the experience economy. Harvard Business Review, 76, 97-105. 
Pine, B. J. II, \& Gilmore, J. H. (1999) The Experience Economy: Work is a Theatre and Every Business a Stage. Harvard Business School Press. Boston, Massachusetts.

Pine, B. J. II, \& Gilmore, J. H. (2011) The Experience Economy, Updated Edition. Harvard Business School Press. Boston, Massachusetts.

Pine, R. (2002). China's hotel industry: serving a massive market. The Cornell Hotel and Restaurant Administration Quarterly, 43(3), 61-70.

Pine, R., \& Qi, P. (2004). Barriers to hotel chain development in China. International Journal of Contemporary Hospitality Management, 16(1), 37-44.

Prinz (2009). More theme hotels. Salenstein, Switzerland: Braun Publishing.

PRWeb (2013). Hotels in China industry research report. Retrieved on June $3^{\text {rd }} 2013$ from http://www.prweb.com/releases/china/hotels/prweb10501565.htm.

Schmitt, B. H., Rogers, D. L., \& Vrotsos, K. L. (2004). There's No Business That's Not Show Business: Marketing In An Experience Culture. New Jersey: Financial Times Prentice Hall.

Smith, N. C. (1999). Ethics and the typology of consumer value, in M. B. Holbrook (Ed.), Consumer value: a framework for analysis and research (pp. 147-158), Routledge Interpretive MarketResearch Series, London \& New York.

Solomon, M. R., \& Englis, B. G. (1994). Reality engineering: Blurring the boundaries between commercial signification and popular culture. Journal of Current Issues \& Research in Advertising, 16(2), 1-17.

Tisdell, C., \& Wen, J. (1991). Foreign tourism as an element in PR China's economic development strategy. Tourism Management, 12(1), 55-67.Torabian, P., \& Arai, S. M. 
(2013). Tourist perceptions of souvenir authenticity: an exploration of selective tourist blogs. Current Issues in Tourism, (ahead-of-print), 1-16.

Wei, X. (2005). A call for market demand in the theme hotel era. Modern Hotels, 9(6).

Welch, J. L. (1985). Focus Groups for Restaurant Research. Cornell Hotel and Restaurant Administration Quarterly, 26(August), 78 - 85.

Wong, K. K. F., \& Cheung, P. W. Y. (1999). Strategic theming in theme park marketing. Journal of Vacation Marketing, 5(4), 319-332

Wood, A. (2005). “The Best Surprise Is No Surprise” Architecture, Imagery, and Omnitopia Among American Mom-and-Pop Motels. Space and Culture, 8(4), 399-415.

Wood, N. T., \& Muñoz, C. L. (2007). 'No rules, just right'or is it? The role of themed restaurants as cultural ambassadors. Tourism and Hospitality Research, 7(3-4), 242-255.

Xiao, Q., Zhang, H. Q., \& Huang, H. (2013). The effects of hotel theme strategy: An examination on the perceptions of hotel guests on theme elements. Journal of China Tourism Research, 9(1), 133-150.

Xiao, X. (2010). Creation and innovation of theme hotels. Chengdu, China: Southwestern University of Finance and Economy Press.

Xiao, Z. (2012, February). Innovations in the development of Star Hotel. Professional Hotel Executives, pp. 62-66.

Xu, J. (Ed.). (2012). A history of the Chinese hospitality industry. Beijing: China Tourism Press.

Yang, L. (2013). Ethnic Tourism and Minority Identity: Lugu Lake, Yunnan, China. Asia Pacific Journal of Tourism Research, (ahead-of-print), 1-19.

Yang, Y., Wong, K. K. F., \& Wang, T. (2012). How do hotels choose their location? Evidence from hotels in Beijing. International Journal of Hospitality Management, 31, 675-685. 
Zhang, H. Q., Pine, R., \& Lam, T. (2005). Tourism and hotel development in China: From political to economic success. Routledge.

Zins, A. H. (1998). Leisure traveler choice models of theme hotels using psychographics. Journal of Travel Research, 36(4), 3-15. 